\title{
Potential effects of correction of inaccuracies of the mini-Wright peak expiratory flow meter on the use of an asthma self-management plan
}

\author{
J F Miles, W Tunnicliffe, R M Cayton, J G Ayres, M R Miller
}

\begin{abstract}
Background - Patient self-management plans for asthma use peak expiratory flow (PEF) meter readings for decisions on adjusting asthma treatment. PEF meters have been shown to be inaccurate and the effect of this inaccuracy on such treatment plans has been determined.
\end{abstract}

Methods - PEF measurements were made by 127 severe asthmatic patients at least twice a day for at least two weeks using a mini-Wright meter. The daily variation from "best" PEF and the within day PEF variability were calculated before and after correction for the meter's known inaccuracy. The effect of this data correction on the number of days when trigger points were reached for changing asthma therapy was then determined.

Results - Continuous PEF readings were available from 114 subjects with a median of 157.5 days of data per subject (range 15-489 days). Correction of the PEF data led to the number of days of satisfactory asthma control being reduced in $72 \%$ of subjects with just one subject showing an increase in satisfactory control. Data correction reduced the percentage of total days of satisfactory control from $46 \%$ to $36 \%$ of days, and increased the days requiring more inhaled steroids from $33 \%$ to $36 \%$. The days on which a course of oral corticosteroids was required increased from $16 \%$ to $23 \%$.

Conclusions - The accuracy of PEF meters significantly influences the interpretation of currently used asthma self-man-

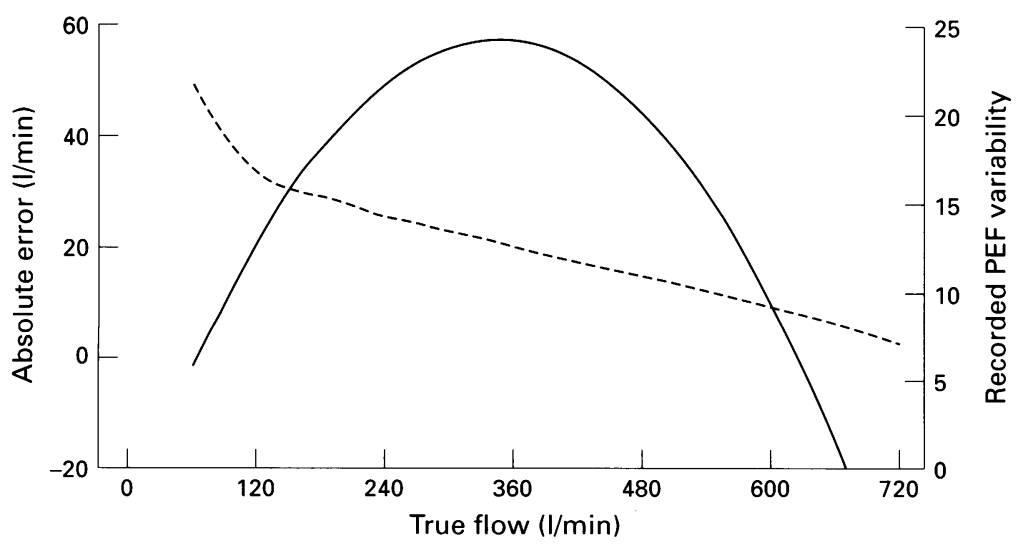

Figure 1 Plot of the absolute error profile (-) of a mini-Wright meter together with a plot of how such a meter would record a true variability in peak expiratory flow (PEF), expressed as amplitude as a percentage of mean, of $15 \%$ (---). agement plans. Managing asthma with the corrected PEF data would have increased the amount of treatment received by these patients since the severity of the asthma was underestimated by the raw data.

(Thorax 1996;51:403-406)

Keywords: asthma, lung function, asthma treatment, peak expiratory flow.

The introduction of portable peak expiratory flow (PEF) meters into the routine management of asthma has led to patients being able to exercise greater control of their condition through self-management plans. ${ }^{12}$ In addition, the peak flow meter is an essential tool for asthma research and epidemiological studies. Although the meters are durable, and are undoubted value for money, doubts have been cast upon the accuracy of their measurements. By the use of a computerised servo-controlled pump, Miller $e t a l^{3}$ were able to demonstrate that certain portable peak flow meters had characteristic error profiles with the meters under reading at lower and higher peak flow values and over reading in the middle range. These non-linear errors have also been found by others ${ }^{4}$ and can cause PEF variability (amplitude percent mean) to be distorted across the range. Figure 1 shows a plot of the typical absolute error in reading with a mini-Wright meter, together with a plot of how such a meter would record a true variability in PEF of $15 \%$. When the true PEF is below about $2001 / \mathrm{min}$ the recorded variability in PEF is an overestimate and above this level it is an underestimate of the true variability.

These errors could theoretically have an important effect on determining the severity of asthma. The mini-Wright peak flow meter is the type most widely used in the United Kingdom so we have studied the effect of correction for its inaccuracy on the use of an asthma selfmanagement plan based on changes in PEF.

\section{Methods}

One hundred and twenty seven patients with severe asthma who were routinely attending an asthma clinic were studied. All had significant asthma and were receiving inhaled corticosteroids at a high dose (at least $1500 \mu \mathrm{g} /$ day). Forty nine patients were known to have a widely variable PEF whilst the others were expected to be prone to exacerbations of asthma occurring against a background of apparently good 
Table 1 Mean 25th, 50th, and 75th percentiles and ranges for the number of days spent by patients with their peak expiratory flow (PEF) in the various PEF ranges

\begin{tabular}{|c|c|c|c|c|c|}
\hline & Mean & $\begin{array}{l}25 \text { th } \\
\text { percentile }\end{array}$ & $\begin{array}{l}\text { 50th } \\
\text { percentile }\end{array}$ & $\begin{array}{l}75 \text { th } \\
\text { percentile }\end{array}$ & Range \\
\hline \multicolumn{6}{|c|}{$>70 \%$ best $\mathrm{PEF}$} \\
\hline Raw & $81 \cdot 5$ & $22 \cdot 3$ & $53 \cdot 5$ & $121 \cdot 0$ & $1-376$ \\
\hline Corrected & $63 \cdot 8$ & $11 \cdot 8$ & $38 \cdot 0$ & $95 \cdot 5$ & $1-302$ \\
\hline \multicolumn{6}{|c|}{$70-51 \%$ best PEF } \\
\hline Raw & $59 \cdot 1$ & $9 \cdot 8$ & $36 \cdot 5$ & $96 \cdot 0$ & $0-328$ \\
\hline Corrected & $62 \cdot 9$ & $10 \cdot 0$ & $41 \cdot 5$ & $99 \cdot 3$ & $0-321$ \\
\hline \multicolumn{6}{|c|}{$50-31 \%$ best PEF } \\
\hline Raw & $27 \cdot 5$ & $0 \cdot 0$ & $6 \cdot 5$ & $41 \cdot 5$ & $0-191$ \\
\hline Corrected & $40 \cdot 8$ & $1 \cdot 0$ & $19 \cdot 0$ & $51 \cdot 3$ & $0-260$ \\
\hline \multicolumn{6}{|c|}{$\leqslant 30 \%$ best $\mathrm{PEF}$} \\
\hline Raw & $8 \cdot 7$ & $0 \cdot 0$ & $0 \cdot 0$ & $3 \cdot 0$ & $0-185$ \\
\hline Corrected & $9 \cdot 2$ & $0 \cdot 0$ & $0 \cdot 0$ & $3 \cdot 3$ & $0-222$ \\
\hline
\end{tabular}

asthma control. Each subject was supplied with a new mini-Wright PEF meter and asked to record on a diary card the best of three PEF readings at least twice but up to four times daily, together with details of their use of asthma medication and their symptoms. Their treatment was adjusted during the study period according to advice given at frequent clinic visits.

The criteria for changes to treatment taken from a standard PEF based self-management plan $^{1}$ were retrospectively applied to these data in the following way to assess the effect of PEF correction on treatment adjustments.

For each subject their "best" PEF was defined as the mean of the five highest PEF recordings made by that patient during the study. The number of patient days where $\mathrm{PEF}$ was $>70 \%$ of best, $51-70 \%$ of best, $31-50 \%$ of best, and $\leq 30 \%$ of best was determined for each subject. These bands represent the trigger points for a change in treatment. ${ }^{1}$ For each day of every subject's data the within day variability in PEF was calculated as the largest within day difference in PEF expressed as a percentage of the maximum PEF on that day. The number of days with a variability of $<10 \%, 11-15 \%$, $16-20 \%, 21-30 \%, 31-40 \%, 41-50 \%$, and $>51 \%$ were determined. Because changes in treatment would usually be instigated when a PEF trigger point was reached, hopefully leading to a subsequent improvement in asthma

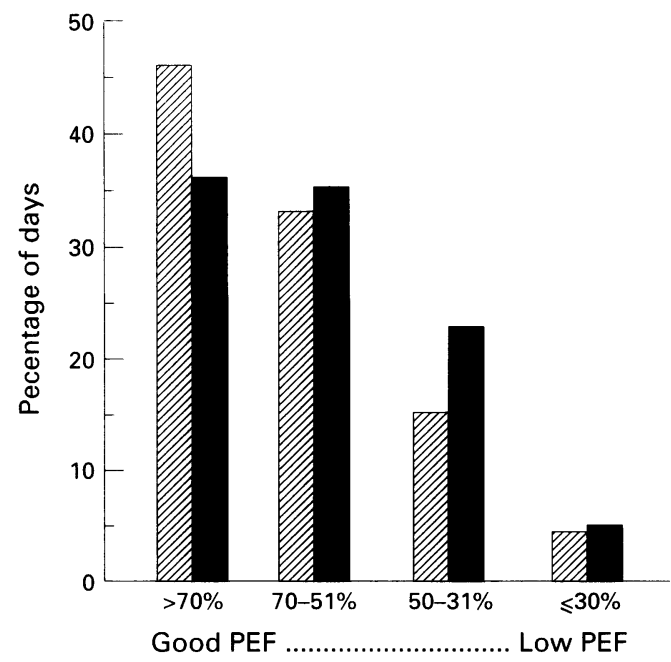

Figure 2 Mean percentage of days for each patient with peak expiratory flow (PEF) in the various categories for the raw (四) and corrected ( ${ }^{\prime}$ data. control over the next two weeks, we calculated the number of instances which were at least 14 days apart when a trigger point was reached.

The relationship between the mean readings from 40 new mini-Wright meters and the true $\mathrm{PEF}$ in $1 / \mathrm{min}$ delivered by a pump system ${ }^{3}$ across a range from 60 to $720 \mathrm{l} / \mathrm{min}$ was found by the method of least squares with the best fit being given by the following equation:

true peak expiratory flow $=$

$0 \cdot 0009 \times \mathrm{PEF}^{2}+0 \cdot 37306 \times \mathrm{PEF}+47 \cdot 4$

where PEF was that recorded by the miniWright meter and the residual standard deviation for the fit was $7 \cdot 1 \mathrm{l} / \mathrm{min}$. The effect of data correction on the PEF data for our subjects was assessed by using the above equation to obtain "true" or corrected PEF from the original raw data and then determining the number of days when trigger points were reached for the corrected data.

Statistical comparisons were made using non-parametric tests as the data were not normally distributed and a probability of less than $5 \%$ was taken as significant.

\section{Results}

Of the 127 patients issued with a new miniWright meter a continuous period of at least 14 days of PEF readings was available in 114 $(90 \%)$, with a median number of continuous days of 157.5 (range 15-489). In the 13 instances where data were unavailable for analysis, refusal to keep accurate records was responsible in 12 , although all but two of these said that they did refer to their meter "from time to time". In the other instance the mere act of such a forced expiratory manoeuvre was capable of provoking a hospital admission with acute asthma and thus the physician in charge had recommended a management strategy based upon symptoms alone. The 114 remaining patients ( 32 men) were all adults of mean age 48 years (range 16-64) with a mean duration of asthma of 17 years (range 12 months to 60 years). A total of 20150 patient days was available for analysis. The mean best PEF for the group was $439 \mathrm{l} / \mathrm{min}$ (25th, 50th and 75 th percentiles being $375,447,509 \mathrm{l} /$ min, respectively, range 192-760) which when corrected was significantly lower at $394 \mathrm{l} / \mathrm{min}$ $(314,395,471 \mathrm{l} / \mathrm{min}$, range $152-851)$, $\mathrm{p}<0.001$, Mann-Whitney test.

When using the raw data $46 \%$ of the total 20150 days of data were deemed to show satisfactory asthma control - that is, PEF greater than $70 \%$ of best - but this was reduced to $36 \%$ of days following data correction (table 1 , fig 2). The proportion of days on which increased inhaled corticosteroids were indicated was changed from $33 \%$ to $36 \%$ by data correction, and for courses of oral corticosteroids the change was from $16 \%$ to $23 \%$ of days. For only $5 \%$ of days did PEF fall to levels that would trigger an admission to hospital and this was unchanged by data correction. The shift towards more time being spent in the PEF range requiring increased inhaled or oral corticosteroids was significant 
Table 2 Number of episodes at least 14 days apart when the peak expiratory flow (PEF) fell in the stated ranges

\begin{tabular}{lll}
\hline & Raw data & Corrected data \\
\hline$>70 \%$ best PEF & 403 & 315 \\
$70-51 \%$ best PEF & 678 & 662 \\
$50-31 \%$ best PEF & 257 & 351 \\
$\leqslant 30 \%$ best PEF & 82 & 92 \\
\hline
\end{tabular}

$\left(\mathrm{p}<0.001, \chi^{2}=555 \cdot 4, \mathrm{df}=3\right)$. A total of 1420 periods of 14 days within the data were available for analysis. The number of instances at least 14 days apart when a trigger point was reached, with and without data correction, is shown in table 2. Data correction significantly increased the number of these periods triggering at $50 \%$ and $30 \%$ of "best" PEF with a reduction in the number of periods of good control or PEF falling below $70 \%$ of "best" $\left(\mathrm{p}<0.001, \chi^{2}=\right.$ $26 \cdot 08, \mathrm{df}=3$ ).

Figure 3 shows the effect of data correction on the number of days recorded with certain degrees of within day PEF variability. In our group of subjects, data correction led to a significant shift towards more days with a higher degree of within day PEF variability $(\mathrm{p}<0.001$, $\left.\chi^{2}=161 \cdot 2, \mathrm{df}=6\right)$.

Table 3 shows the number of patients who had an increase, no change, or a reduction in the number of days with recorded PEF in various $P E F$ ranges when data correction was performed. In 82 patients $(72 \%$ of the total) the number of days at $70-100 \%$ of best PEF was reduced by PEF correction with just one patient having more days of satisfactory control. At each of the other levels of control there was a net increase in the number of subjects having poorer control.

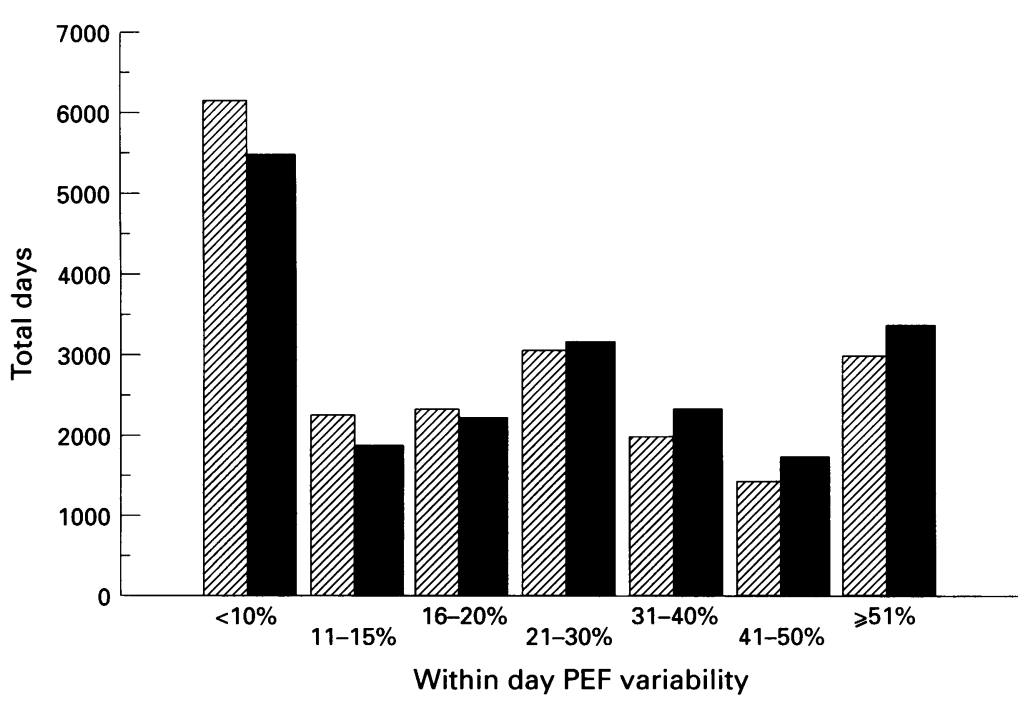

Figure 3 Total number of days where the within day variability in peak expiratory flow $(P E F)$ was within the specified ranges for the raw(ש) and corrected ( $\square$ data.

Table 3 Number of patients (perentage of total subjects) who had an increase, no change, or reduction in the number of days with peak expiratory flow (PEF) in various ranges when data correction was performed

\begin{tabular}{lllll}
\hline & $>70 \%$ of best & $\begin{array}{l}70-51 \% \text { of best } \\
\text { PEF }\end{array}$ & $\begin{array}{l}50-31 \% \text { of best } \\
\text { PEF }\end{array}$ & $\begin{array}{l}\text { S30\% of best } \\
\text { PEF }\end{array}$ \\
\hline Reduced days & $82(72 \%)$ & $35(31 \%)$ & $8(7 \%)$ & $14(12 \%)$ \\
No change & $31(27 \%)$ & $21(18 \%)$ & $36(32 \%)$ & $80(70 \%)$ \\
Increased days & $1(1 \%)$ & $58(51 \%)$ & $70(61 \%)$ & $20(18 \%)$ \\
\hline
\end{tabular}

Discussion

Our analysis has shown that by correcting for the inaccuracy of the mini-Wright PEF meter the timing of the treatment responses to deteriorations in PEF is altered. In addition there is evidence that, if the definition of satisfactory asthma control is the ability to maintain PEF above $70 \%$ of best, then the degree of satisfactory control achieved by our sample has been significantly overestimated when using the raw data for analysis. At PEF levels of $70-51 \%$ and $50-31 \%$ of best PEF, important treatment changes need to be effected, and in up to $61 \%$ of our subjects wrong treatment choices or lost opportunities for treatment would occur if the patients used the raw PEF data for making self-management decisions about their asthma.

It has been recognised that adherence to asthma self-management plans based on PEF measurement significantly improves morbidity ${ }^{15}$ although some authors have argued that the improvement in asthma control is achievable with self-management plans based on symptom changes alone. ${ }^{5}$ We have shown that responses to changes in the PEF reading would be different if a scale corrected for the inaccuracy of the mini-Wright PEF meter was to be used. Future comparative studies of the two types of self-management plan may change current concepts if PEF meters with corrected scales are used. Earlier intervention in response to changes in PEF may also influence outcome in life threatening attacks of asthma, although the evidence that regular PEF monitoring reduces the risk of death from asthma is conflicting and is largely dependent on physician practices rather than the results of formal clinical trials. In studies where domiciliary PEF monitoring has been used it has consistently shown itself to be a marker of severity, ${ }^{6-10}$ although that has not always been enough to prevent fatalities even in the most ideal monitoring conditions. ${ }^{112}$ Patients with severe asthma have been shown to have a poor perception of symptoms, ${ }^{1314}$ hence domiciliary PEF monitoring is an essential part of asthma management in this high risk group.

The efficacy of PEF monitoring for asthma management has recently been questioned ${ }^{1516}$ with the suggestion that PEF monitoring is best suited for the more severe asthmatic patients. ${ }^{15}$ Our subjects fall into the more severe range of asthma and we have shown that the inaccuracy of PEF meters significantly affects the selfmanagement plans for these patients. Since the raw PEF data underestimate the severity of the asthma, it is likely that the benefit of PEF management plans based on PEF monitoring would be greater if the readings were accurate. The degree of effect of this inaccuracy depends on the level of a subject's own variability and where their PEF lies within the range of the meter. ${ }^{3}$ Our patients had a mean PEF in the mid range where the meter error is highest. ${ }^{3}$

Studies on subjects with PEF values all in the low or high range of the meters may give different results from ours, but we believe our subjects to be representative of asthmatics with problematic control who might benefit from 
PEF monitoring. We cannot extrapolate from this study to state that the outcome of an individual patient's asthma treatment would be altered by the effect of the inaccuracy of the PEF meter. The study necessary to prove this would be extremely large and complex. However, our data indicate that the effect of using a PEF meter with correct readings for our subjects would lead to more treatment being given because the severity of changes in PEF was being underestimated and we believe this is likely to be beneficial.

We conclude that the inaccuracy of the PEF meter may reduce the possible benefit achievable from asthma self-management plans, and correction for this inaccuracy will be an important step in ensuring the best treatment for patients with severe asthma. A major part of the benefit from adopting a self-management plan for asthma is that the treatment is applied in a uniform and equitable way. The fact that the meters currently used have an inaccuracy that affects these plans does not negate their benefit, but in the light of the knowledge that this inaccuracy does have an important effect, it will be necessary to correct the inaccuracy of the meters so that all patients can receive the benefit on an equal basis. Whilst a mathematical correction can be applied, as we have done, this is too cumbersome for individual patients. If a profusion of improved and different scales for PEF meters arises, then any possible improvement in asthma management consequent from the use of more accurate scales would be at the expense of increasing confusion about which scale is truly correct. A single agreed international standard for PEF meter scales is required to resolve this problem. ${ }^{17}$

Dr J F Miles was supported during this study by a Sheldon Research Fellowship from the West Midlands Regional Health Authority.

1 Beasley R, Cushley M, Holgate ST. A self management plan in the treatment of adult asthma. Thorax 1989;44: 200-4.

2 Hindi-Alexander MC. Asthma education programs: their role in asthma morbidity and mortality. $\mathcal{F}$ Allergy Clin Immunol 1987;80:492-4.

3 Miller MR, Dickinson SA, Hitchings DJ. The accuracy of portable peak flow meters. Thorax 1992;47:904-9.

4 Gardner RM, Crapo RO, Jackson BR, Jensen RL. Evaluation of accuracy and reproducibility of peak flow meters at $1400 \mathrm{~m}$. Chest 1992;101:948-52.

5 Charlton I, Charlton G, Broomfield J, Mullee MA. Evaluation of peak flow and symptoms only self management plans for control of asthma in general practice. $B M \mathscr{f} 1990$ 301:1355-9.

6 British Thoracic Association. Death from asthma in two regions of England. $B M \mathcal{F}$ 1982;285:1251-5.

7 Hetzel MR, Clark TJH, Branthwaite MA. Asthma: analysis of sudden deaths and ventilatory arrests in hospital. $B M \mathcal{F}$ 1977;1:808-11.

8 Martin RJ, Cicutto LC, Ballard RD. Factors relating to the nocturnal worsening of asthma. Am Rev Respir Dis 1990; 141:33-8.

9 Stableforth DE. Death from asthma. Thorax 1983;38:801-5.

10 Bateman JRM, Clarke SW. Sudden death in asthma. Thorax 1979;34:40-4.

11 Westerman DE, Benatar SR, Potgieter PD, Ferguson AD. Identification of the high-risk asthmatic patient. $A m \mathcal{F} M e d$ 1979;66:565-72.

12 Marquette CH, Saulnier F, Leroy O, Wallaert B, Chopin C, Demarq JM, et al. Long term prognosis of near-fatal C, Demarq JM, et al. Long term prognosis
asthma. Am Rev Respir Dis 1992;146:76-81.

13 Ruffin RE, Latimer KM, Schembri DA. Longitudinal study of near fatal asthma. Chest 1991;99:77-83.

14 Boulet L-P, Deschesnes F, Turcotte H, Gignac F. Nearfatal asthma: clinical and physiologic features, perception of bronchoconstriction and psychologic profile. $\mathcal{F}$ Allergy Clin Immunol 1991;88:838-46.

15 Grampian Asthma Study of Integrated Care (GRASSIC) Effectiveness of routine self monitoring of peak flow in patients with asthma. BMF 1994;308:564-7.

16 Sly PD, Cahill P, Willet K, Burton P. Accuracy of mini peak flow meters in indicating changes in lung function in children with asthma. BMY 1994;308:572-4

17 Miller MR, Quanjer Ph H. Peak flow meters: a problem of scale. BMF 1994;308:548-9. 